\title{
Idiopathic linear interstitial keratitis
}

INSERM

\section{Source}

INSERM. (1999). Orphanet: an online rare disease and orphan drug data base. Idiopathic linear interstitial keratitis. ORPHA:314017

Idiopathic linear interstitial keratitis is a rare, acquired ocular disease characterized by migratory or non-migratory, horizontal, linear, stromal infiltrates that may heal spontaneously. Minimal vascularization and scarring may be observed but vision loss is not associated. 